\title{
A case study: Application of energy and exergy analysis for enhancing the process efficiency of a three stage propane pre-cooling cycle of the Cascade LNG process
}

\author{
Nazreen Begum Najibullah Khan a,b*, Ahmed Barifcani •, Moses Tade •, Vishnu Pareek • \\ "Department of Chemical Engineering, Curtin University of Technology, GPO Box U1987, Perth, Western \\ Australia 6001 \\ bFaculty of Chemical Engineering and Natural Resources University Malaysia Pahang, Lebuhraya Tun Razak, \\ 26300 Gambang, Kuantan, Pahang Darul Makmur, Malaysia
}

\begin{abstract}
The propane pre-cooling cycle has been widely used in most LNG plants as the first cooling cycle in the natural gas liquefaction process. As LNG plants consume high amounts of energy, enhancements in the process design and plant operation will minimize the overall energy consumption of the plant. The aim of this study is to enhance the process efficiency of.J! three stage propane pre-cooling cycle of the Cascade LNG process for the large-scale LNG train by determining the optimal operating conditions of the propane evaporator that will minimize the overall energy consumption. Energy and exergy analysis methods are adopted to evaluate the process efficiency of the propane pre-cooling cycle. Six case studies were presented to determine the optimal operating conditions of the propane evaporator that gives maximum energy reduction. The propane pre-cooling cycle is modelled and simulated using Aspen HYSYS with detailed thermodynamic information obtained to calculate the exergy loss. The results of the energy and exergy analysis indicate that Case 6 gives the highest coefficient of performance (COP) and the maximum exergy efficiency compared to the baseline case, which are $15.51 \%$ and $18.76 \%$ respectively. The results indicate that by reducing the cooling duty at the intermediate stage $\$$. of propane evaporator about $13.5 \%$ energy saving can be achieved compared to the baseline case.
\end{abstract}

Keywords:

propane pre-cooling

exergy loss

refrigeration

cascade cycle

energy optimization 


\section{Introduction}

As the demand on LNG is drastically increasing and the discovery of new large gas fields is continuously taking place worldwide, the pace of change and development in LNG liquefaction technology is becoming more rapid than ever before. LNG production is estimated to hit 320 million tonnes per annum (MTPA) by 2015 and to 450 MTPA by 2020 as reported by Wood [1]. In order to meet this escalating demand, most of the existing and new LNG plants are looking for opportunities to make a further increase in their LNG capacity and building larger LNG trains which will provide economic benefits and be process efficient. Since the 1970s, when the kick started for the LNG plant and until the present day, three main LNG processes have been applied in the LNG plants viz. Single mixed refrigerant (SMR), Propane precooled mixed refrigerant (C3MR) and cascade liquefaction process [2]. In the last 10 to 15 years, the innovations of LNG technologies have drastically progressed whereby new LNG processes have been introduced such as Mixed fluid cascade (MFC), Air Products (AP-X ${ }^{\mathrm{TM}}$ ), Dual mixed refrigerant (DMR) and Parallel mixed refrigerant (PMR) [3]. Most of the existing LNG plants have three main cooling cycles, namely the pre-cooling, liquefying and sub-cooling

cycle. Earlier LNG plants that employed the SMR process did not have the pre-cooling cycle, and instead the natural gas was cooled directly to $-160^{\circ} \mathrm{C}$ using a single mixed refrigerant. The pre-cooling cycle is the first cycle in an LNG process which removes the heat from natural gas to a temperature range between $-30^{\circ} \mathrm{C}$ to $-55^{\circ} \mathrm{C}$ depending on the pre-cooling technology applied. As a result of technological advancement, the pre-cooling cycle can now be designed using either pure refrigerant or mixed refrigerant. Castillo, et al. [4] reported that $95 \%$ of the current LNG plants employ the pre-cooling cycle; $85 \%$ of which are dominated by propane refrigerant compared to mixed refrigerant.

Thermodynamic analysis has been widely used in the LNG plants to determine the sources and locations of the main process irreversibilities that occur within the process or are due to ill!_individual unit operation. Energy analysis or the first law of thermodynamic method only indicates the energy

conservation of the overall process which is measured using two parameters i.e. COP and specific power (SP). However, to locate the irreversibility that occurs within the unit operation of the process, the exergy analysis method is applied. These methods are widely applied by other scholars to evaluate the energy conversion process efficiency. Vatani, et al. [5], Kanoglu [6], Cipolato, et al. [7], Al-Otaibi, et al. [8] and Mehrpooya, et al. [9] applied the energy and exergy analysis methods for analysing the

process efficiency of various LNG processes. In a nutshell, these methods are also widely used in some power plants as mentioned in the following references [10-12].

Converting natural gas to liquid utilizes an extensive amount of energy. According to Alfadala et al. [13], a typical base load LNG plant consumes about 5.5-6 kWh of energy per kgmole of LNG produced . An energy-efficient refrigeration system will enhance the plant operation and provide economic benefits [14]. Several authors have discussed the area of enhancing the efficiency of the pre-cooling cycle.

Paradowski, et al. [15] discussed two operating parameters of the pre-cooling cycle in the C3MR process that can enhance the process efficiency plus debottleneck the existing LNG plant capacity to 5.5 MTPA. The pre-cooling temperature of the low pressure (LP) stage and the propane compressor speed were the operating parameters that were adjusted to meet the new capacity requirement. 


\section{exergy [MW]}

EXHX, loss

ExcoMP,loss

Exv,ioss

EXMIX, loss

EXAC, loss

e

$\mathrm{H}$

n

$\mathrm{p}$

Q

S

To

W exergy loss of heat exchanger [MW]

exergy loss of compressor [MW]

exergy loss of valve [MW]

exergy loss of mixer [MW]

exergy loss of air cooler [MW]

specific exergy $(\mathrm{MJ} / \mathrm{kg})$

enthalpy $(\mathrm{MJ} / \mathrm{kg})$

mass flow rate $[\mathrm{kg} / \mathrm{s}]$

pressure [bar]

refrigeration duty [MW]

entropy [MJ/kg K]

ambient temperature [K]

compressor power [MW]

\author{
Subscripts \\ f fluid \\ inlet \\ o outlet \\ r ratio \\ Greek symbol \\ nex exergy efficiency
}

List of symbols

C2H6 ethane

C2fu ethylene

C3Hs propane

Cfu

methane N2

nitrogen

Abbreviations

AC air cooler

$\overline{\mathrm{E} O \bar{S}} \quad$ equation of state

HP high pressure

HX heat exchanger

LNG liquefied natural gas

LP low pressure

MP medium pressure

MTPA million tonnes per annum

PR Peng Robinson

UA product of overall heat transfer coefficient and heat exchanger area

SP $\quad$ specific power

Castillo et al. [16] studied suitable choices of refrigerants that are applicable for pre-cooling cycle by analysing the effects of various refrigerants (i.e. N2, Cfu, C2H6, C3Hs) on the compressor power using the Linde-Hampson process. It was found that compared to other refrigerants, propane has a higher specific refrigerant effect which makes it the preferred refrigerant to be used in the pre-cooling cycle. Ransbarger [17] studied the comparison between three stage and four stage propane cycles for the cascade LNG process which resulted in a power reduction of $1 \%$; nonetheless the economic evaluations

did not justify the increased cost associated with the additional stage. Evolution in the design of the propane pre-cooling cycle has emerged in recent decades. In this context, various studies have been presented that were related to the enhancement of the efficiency of the propane cycle with respect to significant changes made in the process configuration. Mortazavi, et al. [18] suggested the replacement of the conventional expansion valve in the C3MR process with expanders to improve the liquefaction efficiency. Inanother study, Mortazavi, et al. [19] investigated the usage of waste heat from gas turbines by installing absorption chillers in the propane cycle of the C3MR process. Kalinowski, et al. [20] proposed the replacement of the propane evaporator with an absorption refrigeration system utilizing waste heat from the electrical power generating gas turbines.

Although many studies have been conducted focusing on the efficiency enhancement of the LNG plants through modification of the process configuration [6, 18-21], there is only very scant information available which focuses on the operation perspective. In this study, we to analyse the impact of changing the operating conditions of the propane evaporator towards the energy consumption of the process. Six case studies are proposed with different operating conditions applied to the propane evaporator. The development of these case studies is discussed in section 2.2 of the manuscript. The sensitivity of the COP, the specific power (SP), and the exergy loss and exergy efficiency are analysed for all case studies presented. 
1.1. Description of propane pre-cooling cycle process

Treated feed gas enters the three stage propane cycles at $29^{\circ} \mathrm{C}$ and $75 \mathrm{bar}$ and is cooled to $-40{ }^{\circ} \mathrm{C}$. The propane evaporator (i.e. kettle type) also cools methane and condenses ethylene. Cooling of the process stream is achieved by the evaporation of propane in the pool on the shell side with the process streams

flowing inside the immersed tubes. The propane compressor (i.e. centrifugal type) with side streams recovers the evaporated propane and compresses the vapour to 18 bar. Propane is finally condensed at $49^{\circ} \mathrm{C}$ using the air cooler. The condensed propane is then recycled back to the propane evaporator. Figure 1 shows the simplified process scheme of propane pre-cooling cycle.

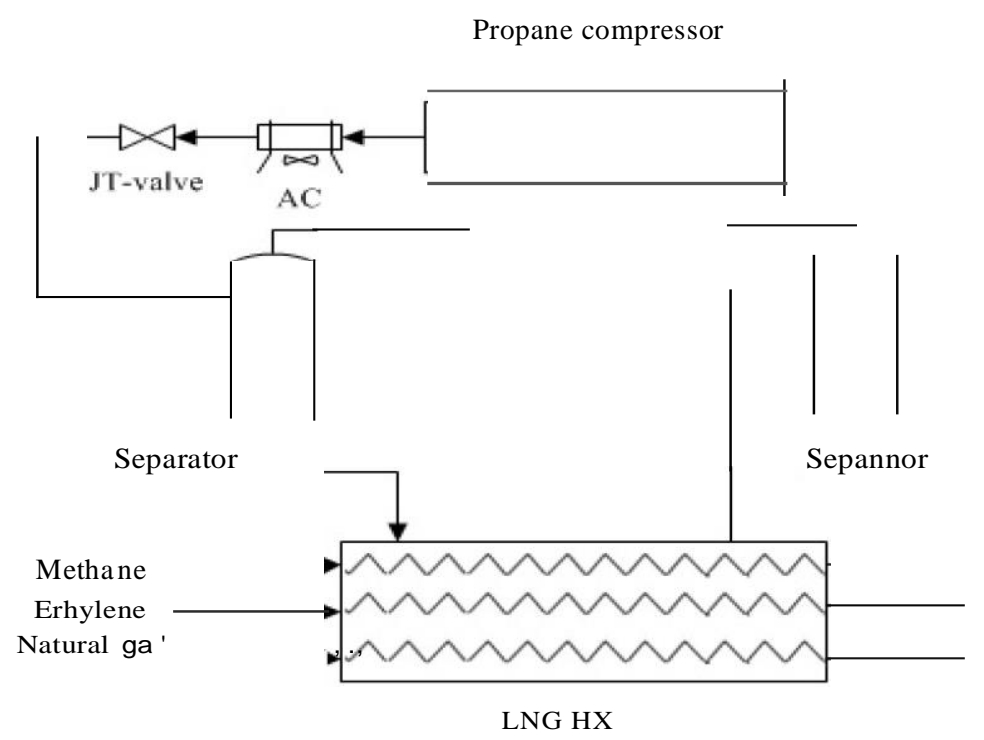

Fig. 1. Simplified process scheme of propane pre-cooling cycle. Only one stage is shown for simplicity.

\section{Simulation method and modelling assumptions}

Aspen HYSYS which is a steady state process modelling software was employed to model the three stage propane pre-cooling refrigeration cycles. Peng Robinson equation of state (PR-EOS) fluid package was used for modelling the property of the substances. This process simulator is well known for modelling the LNG processes and has been widely used by others [22-25]. The feed gas composition and modelling assumptions are summarized in Table 1 and 2 respectively.

Table 1

Feed gas composition after sweetening.

\begin{tabular}{lc}
\hline Component & Mole fraction \\
\hline Nitrogen & 0.0028 \\
Methane & 0.8974 \\
Ethane & 0.0496 \\
Propane & 0.0343 \\
i-Butane & 0.0079 \\
n-Butane & 0.0073 \\
i-Pentane & 0.0005 \\
n-Pentane & 0.0002 \\
n-Hexane & 0.0000 \\
Total & 1.0000 \\
\hline Feed gas composition obtained from Western Australia gas plant
\end{tabular}


Table 2

Modelling assumptions

\begin{tabular}{ll}
\hline Natural gas temperature & $29^{\circ} \mathrm{C}$ \\
Natura gas pressure & $75 \mathrm{bar}$ \\
Catural gas flow rate & $41,700 \mathrm{kgmole} / \mathrm{h}$ \\
Compressor polytropic efficiency & $80 \%$ \\
Pressure drop in LNG heat exchanger & $1.2 \mathrm{bar}$ \\
Pressure dropin air cool heat exchanger & $1.3 \mathrm{bar}$ \\
Minimum temperature approach in heat exchanger & $>2{ }^{\circ} \mathrm{C}$ \\
Ambient temperature & $27^{\circ} \mathrm{C}$ \\
Air cooler exit temperature & $49^{\circ} \mathrm{C}$ \\
\hline
\end{tabular}

\section{The following are the constraints applied in modelling the propane pre-cooling cycle:}

1. Temperature approach (Tapp) in the LNG heat exchanger should be above $2^{\circ} \mathrm{C}$ to prevent temperature cross.

2. The inlet temperature of propane compressor should be above its dew point temperature to safeguard the operation of the compressor.

2.1 Process simulation description In this study, six case studies as shown in Table 3 have been studied with different operating conditions applied at each evaporator stage to analyse the performance of the propane pre-cooling cycle. The operating conditions of the propane evaporator is changed through an expansion valve that is located upstream of each evaporator (i.e.CV-1: HP stage; CV-2: MP stage and CV-3: LP stage) as depicted in Figure 2. The expansion valve pressure is the key manipulated variable that is adjusted to obtain the desired cooling duty for each stage propane evaporator and also to maintain the temperature approach ${ }^{33}$ above $2^{\circ} \mathrm{C}$. Discharge pressure of LP and MP stage propane compressors is connected to the MP and 34 HP propane evaporator stage respectively to obtain the resultant compressor power as shown in Figure 2 and 3. Propane pre-cooling cycle configuration for the baseline case and case 6 are also shown in Figure 2 and 3 respectively and changes made on the operating parameters are marked with dotted lines on these figures.

Table 3

Propane evaporator operating conditions for all case studies.

\begin{tabular}{ll}
\hline Case studies & $\begin{array}{l}\text { Propane evaporator } \\
\text { operating conditions }\end{array}$ \\
Case 1• & $-2 \mathrm{~s} \cdot \mathrm{C},-3 \mathrm{O} \cdot \mathrm{C},-4 \mathrm{o} \cdot \mathrm{C}$ \\
Case 2 & $-1 \mathrm{~s} \cdot \mathrm{C},-2 \mathrm{o} \cdot \mathrm{C},-4 \mathrm{O} \cdot \mathrm{C}$ \\
Case 3 & $-10 \cdot \mathrm{C},-1 \mathrm{~s} \cdot \mathrm{C},-4 \mathrm{O} \cdot \mathrm{C}$ \\
Case 3 & $\mathrm{SC},-1 \mathrm{O}^{\circ} \mathrm{C},-4 \mathrm{O} \cdot \mathrm{C}$ \\
Case $\mathrm{S}$ & $\mathrm{O} \cdot \mathrm{C}, \mathrm{SC},-4 \mathrm{O} \cdot \mathrm{C}$ \\
Case 6 & $5^{\circ} \mathrm{C}, \mathrm{O} \cdot \mathrm{C},-4 \mathrm{O} \cdot \mathrm{C}$ \\
$\cdot\left(-25^{\circ} \mathrm{C},-30^{\prime \prime} \mathrm{C},-40^{\circ} \mathrm{C}\right.$ means process exit temperature at HP, MP and LP stage respectively $)$
\end{tabular}




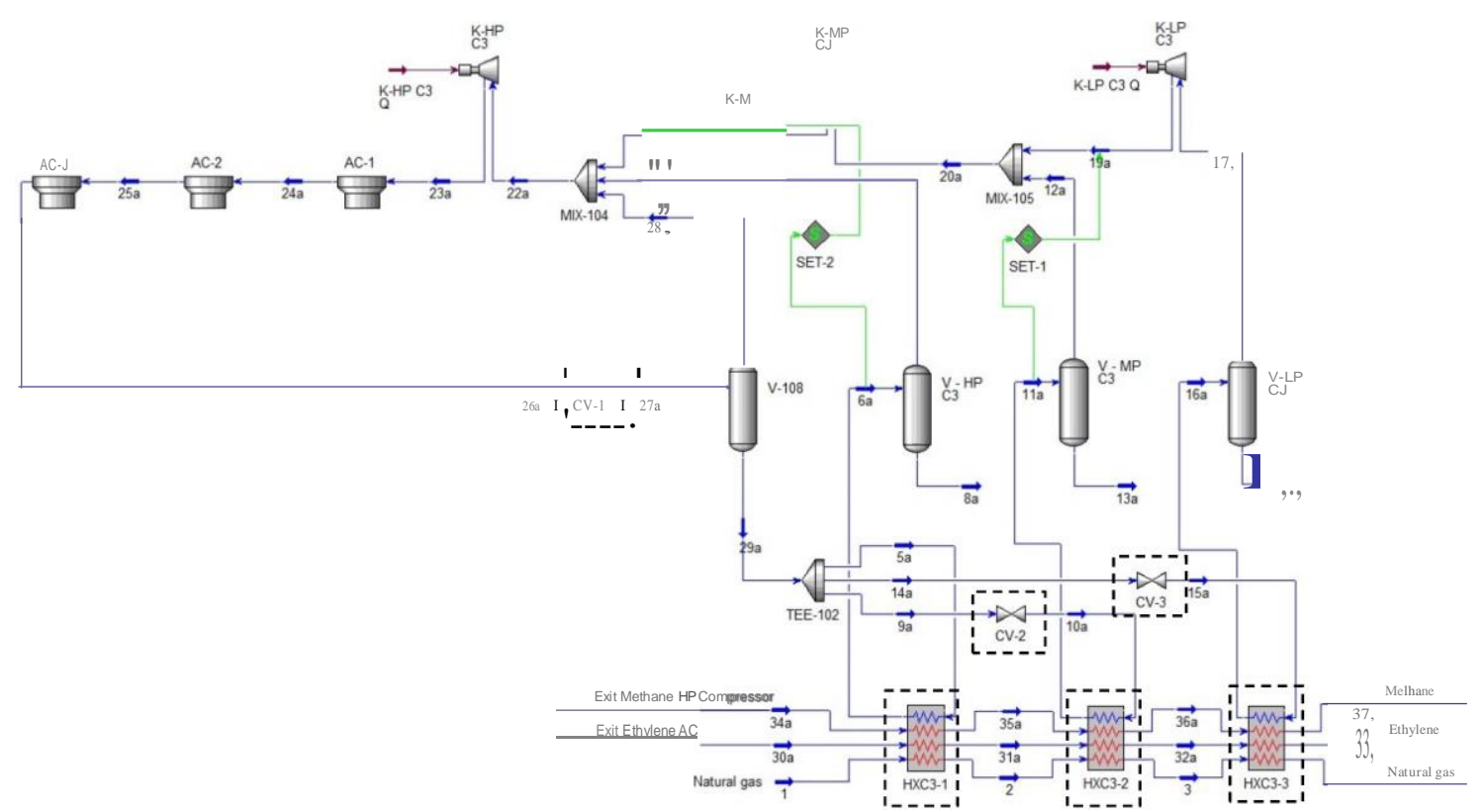

Fig. 2. Propane pre-cooling cycle Case 1 configuration.

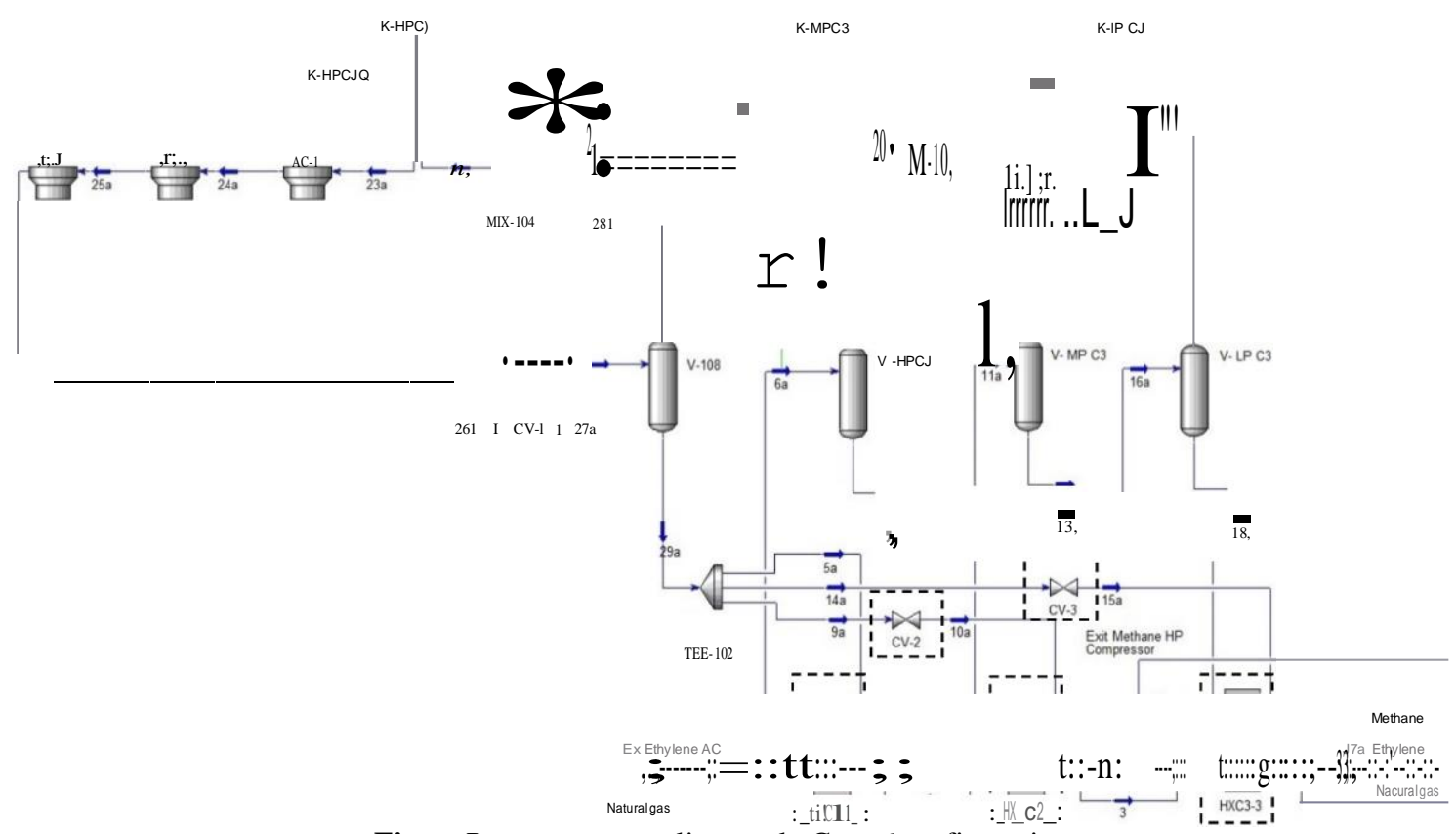

Fig. 3. Propane pre-cooling cycle Case 6 configuration.

2.2 Case studies development of propane pre-cooling cycle These six case studies were derived by analysing various operating conditions of current LNG plants located in Southeast Asia region, Australia and also based on the information available from the literature $[6,15-21,26]$. Figure 4 illustrates the development of the propane pre-cooling cycle case studies.

Case studies presented are defined as follows:

Case 1:Baseline case (i.e. higher cooling duty at the intermediate stage§. (i.e. HP and MP stage) 
Case 6:(i.e. lower cooling duty at intermediate stage§.) 


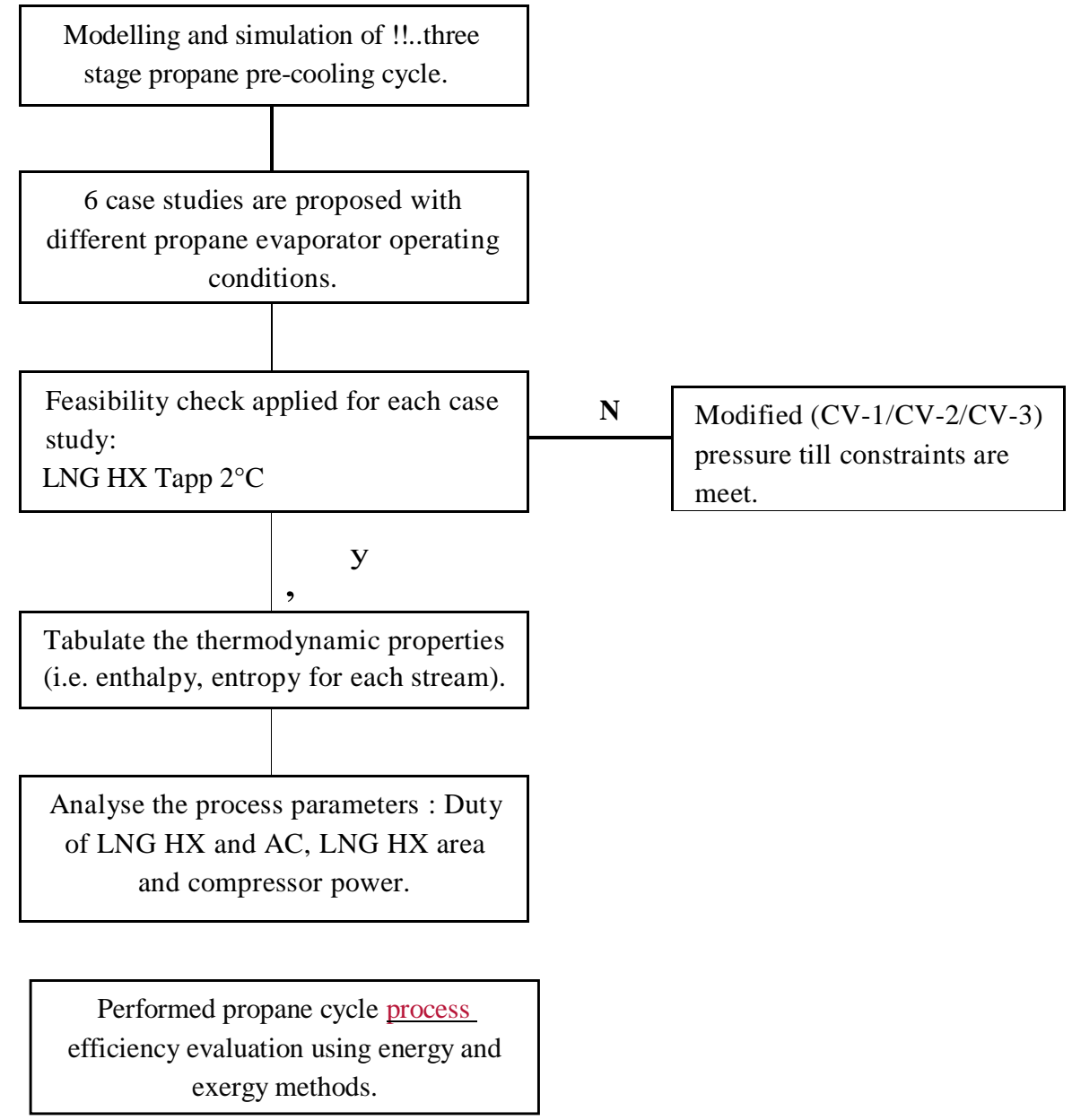

Fig. 4. Development of propane pre-cooling cycle case studies.

\section{Energy analysis}

Energy consumption and process efficiency of the overall process are determined through energy analysis. This method has two quantitative parameters; COP and SP.COP is a standard criterion applied in evaluating the efficiency of a cryogenic system. It is defined as the ratio of total heat removed by refrigerant to the amount of power required by the system (Eq. 1) while SP is defined as total power consumption per unit mass of LNG (Eq. 2).

$\mathrm{COP}=\mathrm{QIW}$

$\mathrm{SP}(\mathrm{MWh} /$ tonne $\mathrm{LNG})=L \mathrm{~W}$, eq $I_{\text {ffiLNG }}$

where the nomenclature for the above equations are as follows: $Q$ is refrigeration duty (MW); $\mathrm{W}$ is compressor power (MW), $L$ wreq is the total compressor power required (MW) and ffiLNG is the amount of LNG produced in tonne/h. 
3.1.Exergy analysis

In this study, exergy analysis is applied to locate the irreversibility that occurs within the unit operations of the propane pre-cooling cycle. This method identifies the individual unit operation that exhibits a higher amount of lost work which gives the process engineer valuable information for improving the

process from the equipment and process design point of view. Exergy which is derived from the second law of thermodynamics is defined as the amount of reversible work achieved by a system when the system components are brought into thermodynamic equilibrium state with its environment in a reversible process [27]. The exergy change of a system is a function of two main parameters which are the enthalpy and entropy. Change in exergy $<$ ) between the initial and the final state of a system is expressed as:

$\Delta \mathrm{E}_{\mathrm{x}}=\left(\mathrm{H}_{\mathrm{o}}-\mathrm{H}_{\mathrm{i}}\right)-\mathrm{T}_{\mathrm{o}}\left(\mathrm{S}_{\mathrm{o}}-\mathrm{S}_{\mathrm{i}}\right)$

where $T_{0}$ is the ambient temperature, $H_{0}$ and $S_{0}$ represent the enthalpy and entropy of the outlet stream and $H i$ and $S i$ represent the enthalpy and entropy of the inlet stream respectively. The difference of this property will define whether the processing system requires or produces work as the systems moves

from initial state to final state. If the exergy difference (Lllix) is greater than 0 , this indicates that the processing system produces work, whereas if the exergy difference is less than 0 , this indicates the processing system requires work from the outer system for the state change [28].

The exergy efficiency of the process is defined as the ratio of the difference between the total compressor power required and the total exergy loss to the total amount of power required by the system (Eq.4). The exergy efficiency is expressed as:

$$
\begin{aligned}
& \text { 1)ex }(\%)=\mathrm{U}: \mathrm{wreq}-L \mathrm{w} \text { loss) } \mathrm{x} 100 \text { [6] } \\
& \text { L Wreq }
\end{aligned}
$$

where $L$ wloss is the total exergy loss work from each unit operation.

The expressions to determine the exergy loss for all the unit operations in this study are summarized in Table 4. 
Table 4

Exergy loss calculation of various unit operations in propane cycle.

LNG heat

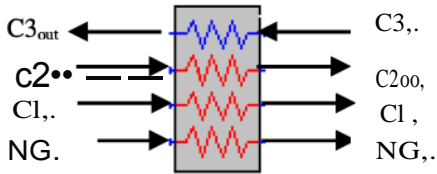

$\mathrm{Ex}_{\mathrm{HX}}$, loss $=\dot{\mathrm{m}} \sum \mathrm{ex}_{\mathrm{i}}-\mathrm{ex}_{\mathrm{o}}$

Compressor

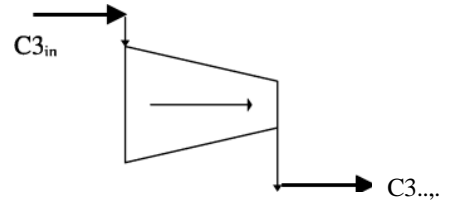

$\mathrm{Ex}_{\mathrm{COMP}, \text { loss }}=\dot{\mathrm{m}}\left(\mathrm{ex}_{\mathrm{i}}-\mathrm{ex}_{\mathrm{o}}\right)-\mathrm{W}$

Valves

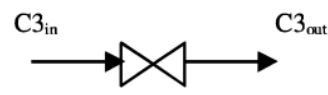

$\mathrm{Ex}_{\mathrm{V}, \text { loss }=}=\dot{\mathrm{m}}_{\mathrm{o}}\left(\mathrm{S}_{\mathrm{o}}-\mathrm{S}_{\mathrm{i}}\right), \mathrm{h}_{\mathrm{i}}=\mathrm{h}_{\mathrm{o}}$

Mixer

3

$\mathrm{Ex}_{\mathrm{MIX}, \text { loss }=} \dot{\mathrm{m}}_{1} \mathrm{e}_{1}+\dot{\mathrm{m}}_{2} \mathrm{e}_{2}-\dot{\mathrm{m}}_{3} \mathrm{e}_{3}$

Air cooler

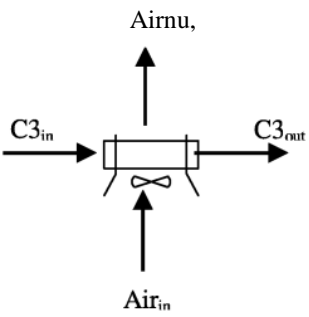

$\mathrm{Ex}_{\mathrm{AC}, \text { loss }}=\left(\dot{\mathrm{m}}_{\mathrm{f}} \mathrm{e}_{\mathrm{f}}+\dot{\mathrm{m}}_{\mathrm{a}} \mathrm{e}_{\mathrm{a}}\right)_{\mathrm{i}}-\left(\dot{\mathrm{m}}_{\mathrm{f}} \mathrm{e}_{\mathrm{f}}+\dot{\mathrm{m}}_{\mathrm{a}} \mathrm{e}_{\mathrm{a}}\right)_{\mathrm{o}}$

In the above equations, th is the mass flow rate of propane at the inlet stream $(\mathrm{kg} / \mathrm{s}), \mathrm{W}$ is the compressor power (MW), S is the entropy (MJ/kg.K), th a is the mass flow rate of air in $(\mathrm{kg} / \mathrm{s})$ and e is the specific exergy for the respective stream in $(\mathrm{MJ} / \mathrm{kg})$.

Thermodynamic analysis comprising of the first and second law is used in this study to overcome the limitations of the deterministic optimization method i.e. a numerical approach which excludes the uncertainty changes involved in the design process, hence it is not considered as the best option for many actual engineering problems [29]. Additionally, the optimization result obtained using this method causes ambiguity because it is not embedded with any process knowledge (i.e. enthalpy and entropy) [23]. Knowing these important process parameters for each process stream provides a better understanding of the changes occurring within the process. Hence, necessary adjustment can be done on the operating parameter to improve the process performance. 


\section{Results and discussion}

Operating conditions of the baseline (Case 1) and Case 6 are summarized in Table 5. The effect of different operating conditions at each evaporator stage on the heat exchangers, compressors and air coolers are discussed in the section 4.1.

Table 5

Operating conditions of each stream in propane refrigeration cycle.

\begin{tabular}{|c|c|c|c|c|c|c|c|c|}
\hline \multirow[b]{2}{*}{$\begin{array}{c}\text { Stream } \\
\text { no }\end{array}$} & \multicolumn{4}{|c|}{ (Case 1) } & \multicolumn{4}{|c|}{ Case 6} \\
\hline & $\mathrm{x}$ & $\mathrm{T}(\mathrm{OC})$ & $\mathrm{P}(\mathrm{bar})$ & $\mathrm{S}(\mathrm{kJ} / \mathrm{kg} \mathrm{K})$ & $\mathrm{x}$ & $\mathrm{T}(\mathrm{OC})$ & $\mathrm{P}($ bar $)$ & $\mathrm{S}(\mathrm{kJ} / \mathrm{kg} \mathrm{K})$ \\
\hline 1 & 1 & 29 & 75 & 7.98 & 1 & 29 & 75 & 7.98 \\
\hline 2 & 0.99 & -25 & 74.80 & 7.34 & 1 & 5 & 74.80 & 7.74 \\
\hline 3 & 0.98 & -30 & 74.60 & 7.25 & 1 & 0 & 74.60 & 7.69 \\
\hline 4 & 0.92 & -40 & 74.40 & 7.02 & 0.92 & -40 & 74.40 & 7.02 \\
\hline $\mathrm{Sa}$ & 0 & -27.49 & 1.85 & 1.56 & 0 & 2.12 & 5.05 & 1.84 \\
\hline $6 a$ & 1 & -23 & 1.85 & 3.26 & 1 & 7 & 5.05 & 3.23 \\
\hline $7 a$ & 1 & -23 & 1.85 & 3.26 & 1 & 7 & 5.05 & 3.23 \\
\hline $\mathrm{Sa}$ & 0 & -23 & 1.85 & 1.60 & 0 & 7 & 5.05 & 1.88 \\
\hline $9 a$ & 0 & -27.49 & 1.85 & 1.56 & 0 & 2.12 & 5.05 & 1.84 \\
\hline $10 a$ & 0.02 & -32.34 & 1.53 & 1.56 & 0.03 & -2.96 & 4.32 & 1.84 \\
\hline $11 a$ & 1 & -27 & 1.53 & 3.27 & 1 & 2 & 4.32 & 3.23 \\
\hline $12 a$ & 1 & -27 & 1.53 & 3.27 & 1 & 2 & 4.32 & 3.23 \\
\hline $13 a$ & 0 & -27 & 1.53 & 1.57 & 0 & 2 & 4.32 & 1.84 \\
\hline $14 a$ & 0 & -27.49 & 1.85 & 1.56 & 0 & 2.12 & 5.05 & 1.84 \\
\hline $15 a$ & 0.07 & -42.19 & 1.01 & 1.57 & 0.24 & -42.19 & 1.01 & 1.88 \\
\hline $16 a$ & 1 & -33 & 1.01 & 3.32 & 1 & -25 & 1.01 & 3.37 \\
\hline $17 a$ & 1 & -33 & 1.01 & 3.32 & 1 & -25 & 1.01 & 3.37 \\
\hline $18 a$ & 0 & -33 & 1.01 & 1.57 & 0 & -25 & 1.01 & 1.59 \\
\hline $19 a$ & 1 & -16.34 & 1.53 & 3.34 & 1 & 35.95 & 4.32 & 3.43 \\
\hline $20 a$ & 1 & -19.77 & 1.53 & 3.32 & 1 & 34.91 & 4.32 & 3.43 \\
\hline $21 a$ & 1 & -11.98 & 1.85 & 3.33 & 1 & 41.83 & 5.05 & 3.43 \\
\hline $22 a$ & 1 & -24.25 & 1.85 & 3.25 & 1 & 24.18 & 5.05 & 3.33 \\
\hline $23 a$ & 1 & 79.88 & 18 & 3.35 & 1 & 85.16 & 18 & 3.38 \\
\hline $24 a$ & 1 & 70 & 17.70 & 3.29 & 1 & 70 & 17.70 & 3.29 \\
\hline $25 a$ & 1 & 60 & 17.40 & 3.23 & 1 & 60 & 17.40 & 3.23 \\
\hline $26 a$ & 0 & 49 & 17.10 & 2.28 & 0 & 49 & 17.10 & 2.28 \\
\hline $27 a$ & 0.50 & -27.48 & 1.85 & 2.40 & 0.35 & 2.12 & 5.05 & 2.32 \\
\hline $28 a$ & 1 & -27.48 & 1.85 & 3.23 & 1 & 2.12 & 5.05 & 3.20 \\
\hline $29 a$ & 0 & -27.48 & 1.85 & 1.56 & 0 & 2.12 & 5.05 & 1.84 \\
\hline $30 a$ & 1 & 49 & 24.10 & 5.38 & 1 & 49 & 24.10 & 5.38 \\
\hline $31 a$ & 0 & -25 & 23.90 & 3.67 & 1 & 5 & 23.90 & 5.11 \\
\hline $32 a$ & 0 & -30 & 23.70 & 3.60 & 1 & 0 & 23.70 & 5.08 \\
\hline $33 a$ & 0 & -40 & 23.50 & 3.46 & 0 & -40 & 23.50 & 3.46 \\
\hline $34 a^{8}$ & 1 & -10.01 & 36.50 & 9.17 & - & - & - & - \\
\hline 3Sah & 1 & -25 & 36.30 & 9.02 & - & - & - & - \\
\hline $36 a$ & 1 & -30 & 36.10 & 8.97 & $\begin{array}{c}1.00 \\
\end{array}$ & -9.97 & 36.50 & 9.17 \\
\hline $37 a$ & 1 & -40 & 35.90 & 8.86 & 1 & -40 & 36.30 & 8.86 \\
\hline
\end{tabular}

methane stream enters HXC3-3. Refer to Fig. 4 for the configuration. 
4.1 Results of different operating conditions of propane evaporator on the process parameters A._simple and practical way of minimizing the energy consumption of a process is by adjusting the operating conditions of $\mathrm{g}$. Based on the case studies presented, different propane evaporator operating conditions affect the overall energy consumption of the process. As depicted in Figure 5, Case 6

consume§. the lowest compression power and air cooler duty which are 129.36 MW and 342.60 MW respectively compared to the baseline case. This can be translated into an energy saving of $13.5 \%$ and $5.57 \%$ for the compressor power and air cooler duty respectively. Meanwhile, as can be seen in Figure 6, the total propane flow rate of Case 6 is also reduced by $8.6 \%$ compared to the baseline case. Though, the overall duty of the propane evaporator remains constant, having a greater cooling duty at

the intermediate stage§. of propane evaporator result§. in the increased of power consumption, air cooler duty and propane flow rate which reduces the process efficiency.

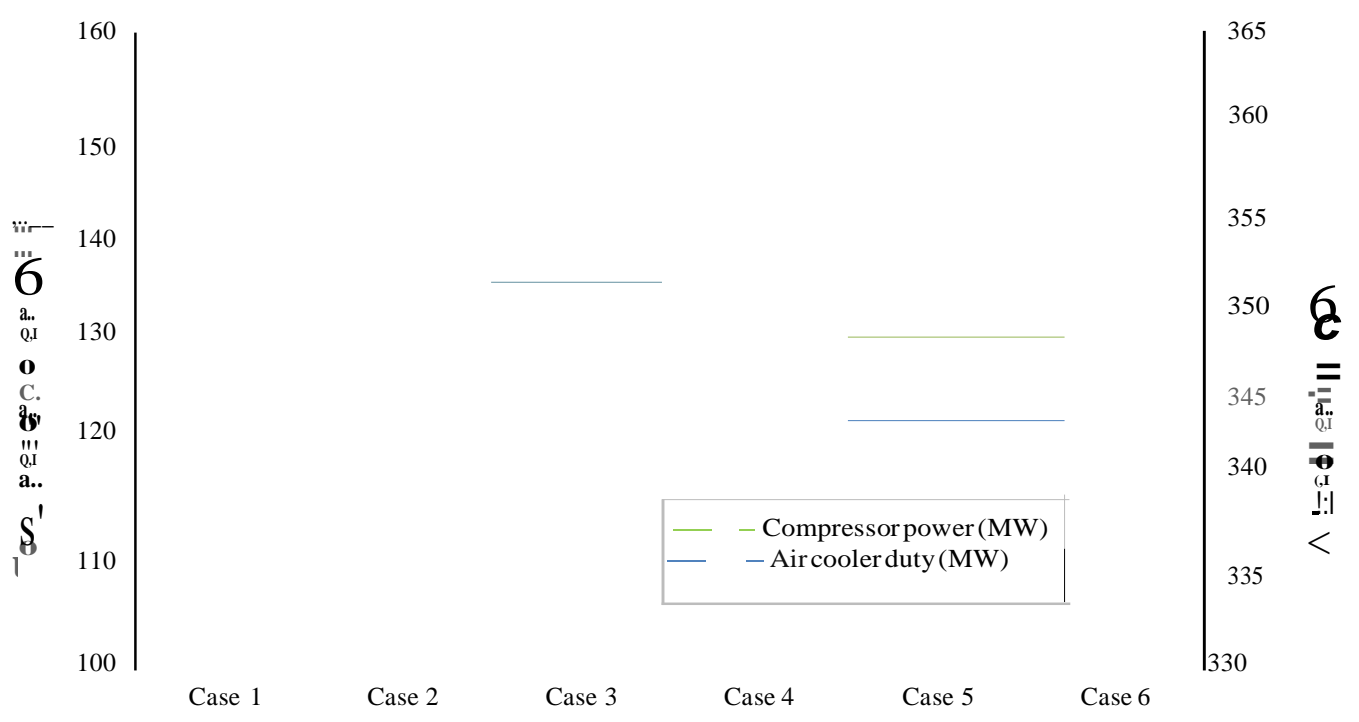

Case studies

Fig. 5. Effect of different operating conditions of propane evaporator on compressor power and air cooler duty.

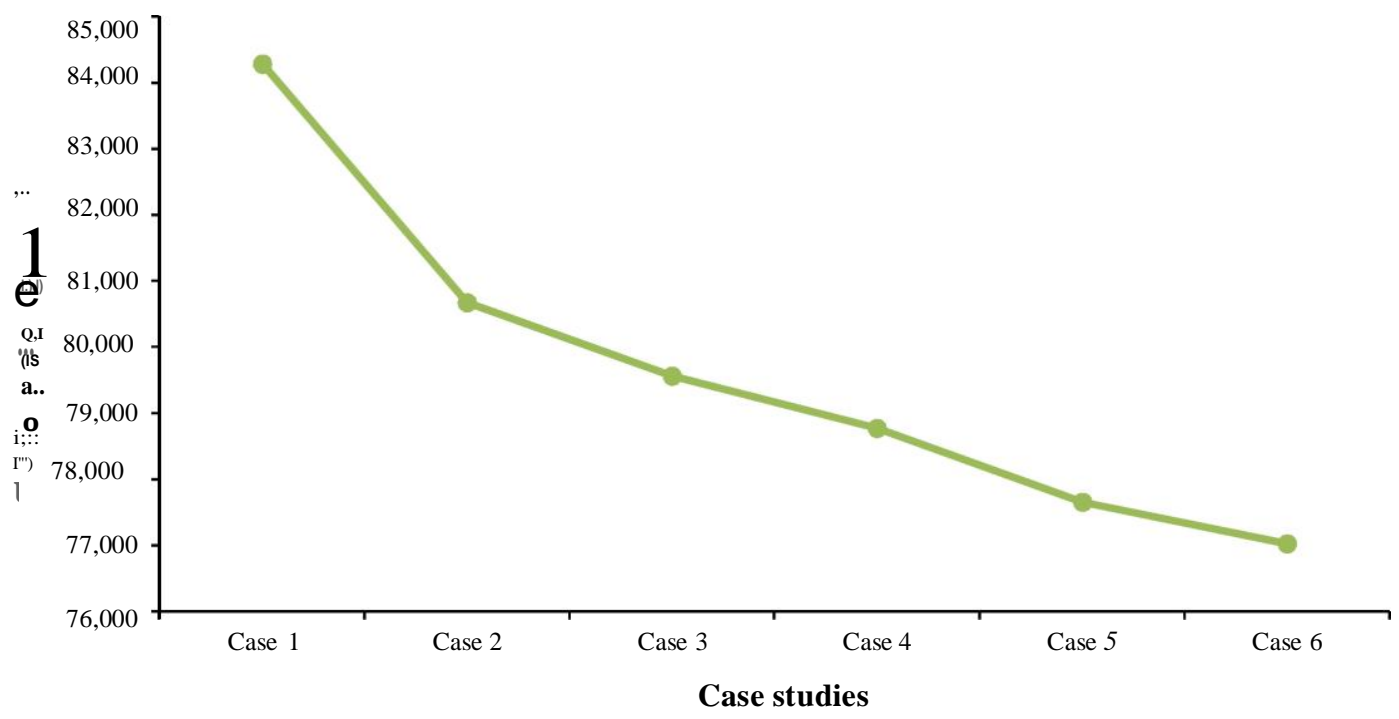

Fig. 6. Effect of different operating conditions of propane evaporator on propane flow rate. 
Distribution of the propane evaporator duty at each stage and its total area required for all case studies are reported in Figure 7 and Table 6. As can be seen in Figure 7, the cooling duty is transferred from the HP stage to the LP stage of propane evaporator (i.e. Case 1 to Case 6). Duty of the propane evaporator is determined using (Eg. 5).Rearranging (Eg.5) gives (Eg. 6) which is used to determine the propane evaporator area. The overall heat transfer coefficient (U) for propane refrigeration cycles was taken as an average value of $425 \mathrm{~W} /\left(\mathrm{m}^{2} . \mathrm{K}\right)$ [30]. Based on this $\mathrm{U}$ value, the propane evaporator area for each case was determined. As shown in Table 6, Case 6 gives the lowest propane evaporator area for the same cooling duty which is $46.89 \%$ lower compared to the baseline case (Case 1). This indicate§. that increasing the cooling duty at the intermediate stage§. of the propane evaporator results in the increased of the total propane evaporator area.

$Q=U A I l T L M T D$

whereby $A=Q l\{U . l l h M T v J$

$Q=$ Duty of heat exchanger $(M W)$

$U=$ Overall heat transfer coefficient $\left(M W / \mathrm{m}^{2}{ }^{\circ} \mathrm{C}\right)$

IITIMTD $=\log$ min temperature difference $\left({ }^{\circ} \mathrm{C}\right)$

$A=$ heat exchanger area $(\mathrm{m} 2)$

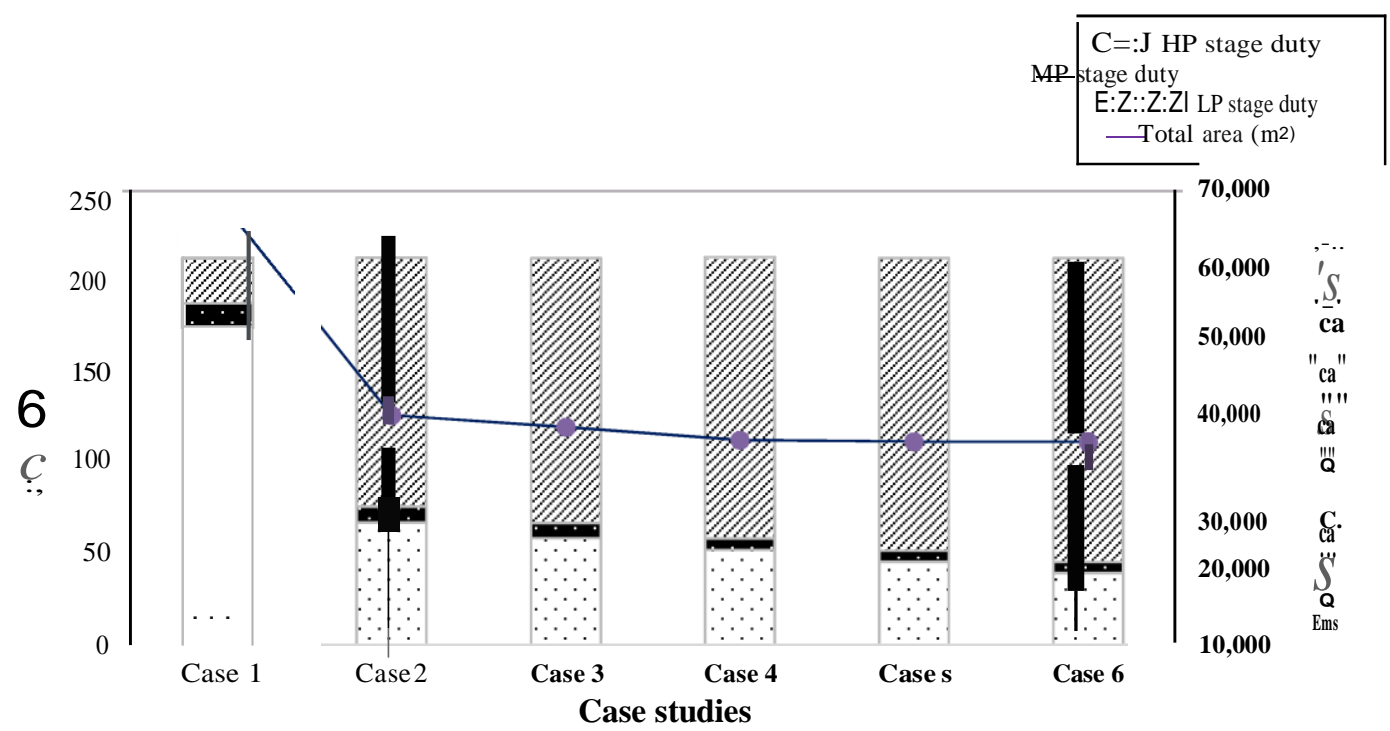

Fig. 7. Effect of different operating conditions of propane evaporator on its duty and total area.

Table 6

Propane evaporator duty for each stage and its total area for all case studies.

\begin{tabular}{ccccccc} 
& Case 1 & Case 2 & Case 3 & Case 4 & Case s & Case 6 \\
\hline Duty & & & & & & \\
$($ MW) & & & & & & \\
HP & 176.20 & 67.34 & 58.65 & 52.19 & 45.64 & 39.42 \\
MP & 12.21 & 8.72 & 8.36 & 6.33 & 6.13 & 5.98 \\
LP & 24.92 & 137.28 & 146.27 & 155.46 & 161.47 & 167.84 \\
$\begin{array}{c}\text { Total area } \\
(\mathbf{m} 2)\end{array}$ & $69,183.61$ & $40,320.54$ & $38,753.54$ & $37,047.88$ & $36,826.10$ & $36,746.38$ \\
\hline
\end{tabular}


4.2 Sensitivity analysis of propane pre-cooling cycle

In this study, the sensitivity of COP, SP, exergy loss and exergy efficiency of the propane pre-cooling cycle were analysed with respect to different operating conditions of the propane evaporator. Effect of different evaporator operating conditions on COP and SP are presented in Figure 8. The exergy loss and exergy efficiency results are shown in Table 7 and Figure 9.

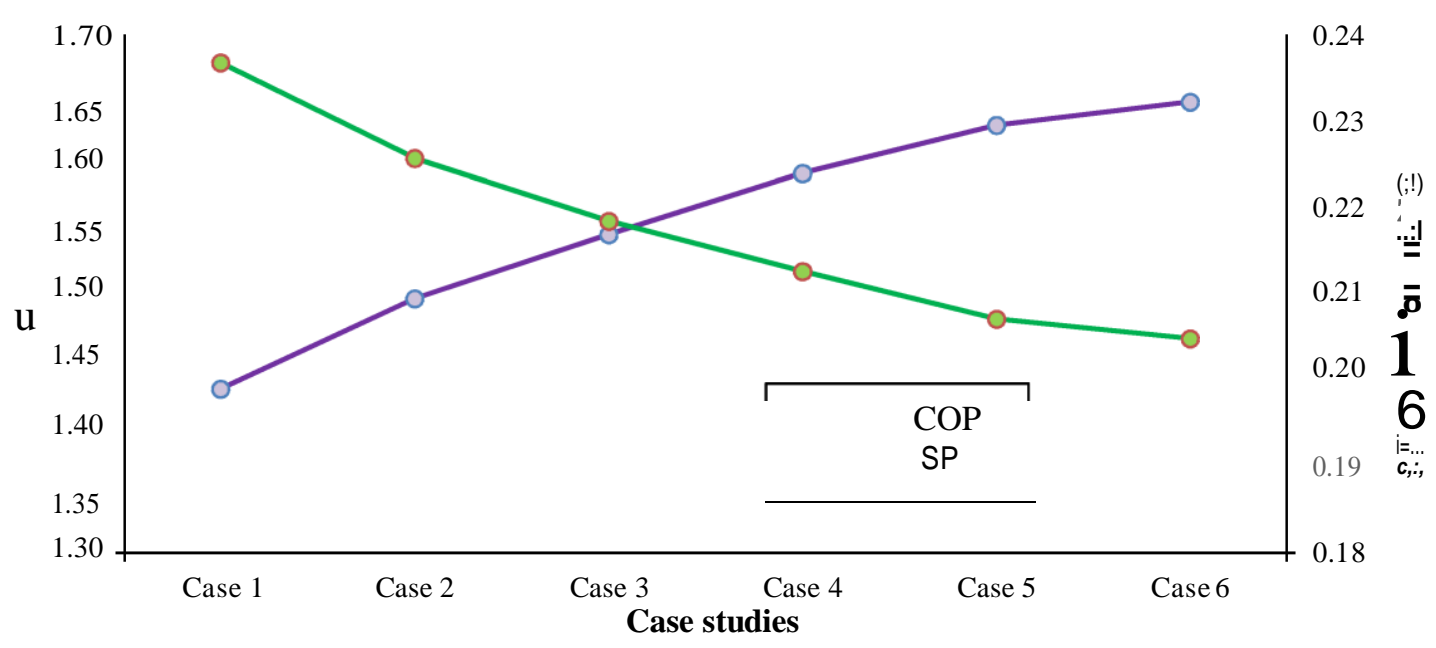

Fig. 8. Effect of different operating conditions of propane evaporator on COP and SP.

As can be seen in Figure 8, the COP of Case 6 increase $\$$. by $15.51 \%$ while the SP reduces by $13.5 \%$ in comparison to the baseline case ( ase 1).Based on the above observation, the required shaft power can be minimized by reducing the cooling duty at the intermediate stage§. of the propane evaporator.

Variation of the cooling duty in the propane evaporator is achieved by manipulation of the expansion valve which i§. located prior to each stage.

Table 7

Exergy loss of each unit operation in propane cycle and exergy efficiency (\%).

$\begin{array}{ccccccc}\text { Exergy loss (MW) } & \text { Case 1 } & \text { Case 2 } & \text { Case 3 } & \text { Case 4 } & \text { Case s } & \text { Case 6 } \\ \text { Heat exchangers } & 16.63 & 20.34 & 20.01 & 20.02 & 19.78 & 20.00 \\ \text { Compressors } & 30.89 & 28.55 & 27.45 & 26.56 & 25.73 & 25.35 \\ \quad \text { Valves } & 38.52 & 28.62 & 25.66 & 22.90 & 20.69 & 19.37 \\ \text { Air coolers } & 12.74 & 12.20 & 13.08 & 11.61 & 11.77 & 11.49 \\ \quad \text { Mixer } & 0.08 & 0.76 & 0.85 & 0.96 & 1.04 & 1.11 \\ \text { 1] } \mathbf{e x}(\%) & 33.87 & 36.52 & 36.89 & 38.90 & 39.58 & 40.22\end{array}$


Fig. 9. Total exergy loss for each case studies.

Exergy loss for each unit operation in the propane pre-cooling cycle was determined using the equations as presented in Table 4. As shown in Table 7, the valves, compressors and heat exchangers were identified as the primary contributors to the exergy loss in the propane cycle. For the baseline case

(Case 1), the valves allocated the highest exergy loss $38.52 \%$, followed by the compressors, $30.89 \%$ and the heat exchangers, $16.63 \%$. Valves provided the highest exergy loss in the baseline case due to increase in entropy generation when larger pressure drop is applied across the system. Compressors are the second contributor in exergy loss due to the increase in power demand when increase in cooling duty occurred at the intermediate stage§. However, for all other case studies the exergy loss across the other components reduced marginally when a lower cooling duty was applied at the intermediate stage§. The exergy efficiency of Case 1 is the lowest $\{33.87 \%$ which indicates that larger irreversibilities occur within the process. Case 6 show $\$$ the highest exergy efficiency $\{40.22 \% 1$ which indicates high potential improvement of the process. Based on Figure 9, the total exergy loss decrease $\$$ by $21.78 \%$ for Case 6 compared to the baseline case which improved the overall process efficiency. From the results it can be deduced that change in the operating conditions of the propane evaporator results in a lower entropy generation which reduces the exergy loss and increases the exergy efficiency. Exergy loss is influenced by larger temperature or pressure difference applied across the refrigerant stream and not by the number of equipment used in the propane cycle [31].

Based on the exergy analysis, it can be concluded that both the valves and the compressors are the main contributors of exergy loss. These unit operations can be improved by replacing the existing JT valves

with two phase expanders [18] or by using a higher efficiency compressor [32]. Nevertheless, the reduction in the energy consumption by installing these new components should be economically assessed to determine its feasibility. 


\section{Conclusion}

In this study, enhancement in the process efficiency of three stage propane pre-cooling cycle was studied using energy and exergy analysis. The results shows that Case 6 achieve§. the highest COP (1.65), lowest SP (0.205 MWh/tonne of LNG) and highest exergy efficiency .(40.22\%). due to low

cooling duty distribution at the intermediate stage§.. Energy and exergy analysis can be a useful guide in enhancing the process efficiency of the existing LNG plant and also as a reference for future greenfield LNG projects . Changing the operating conditions of propane evaporator stage can be considered as an option to minimize energy consumption of the process which does not involve any additional cost. Additionally, this enhancement not only reduces the propane compression power but

also reduces the size of the heat exchanger as well as the refrigeration rate. Reducing energy consumption lead§. to smaller equipment sizes which generally reduce the capital and operating costs of the LNG plants.

\section{Recommendations}

In this study, no consideration is made from economic point of view. As this process is considered as licensed processed, cost related to the proprietary equipment such as compressor and heat exchanger are treated confidential. Thus, the detailed breakdowns on the equipment size, price, licensing fees are not available. Therefore, future work is to be considered which simultaneously provide the trade-off between the capital and operating cost of the plant with exergy analysis.

\section{Acknowledgement}

The authors wish to acknowledge the Ministry of Education (MOE) of Malaysia and University Malaysia Pahang for funding the presented study. The authors also wish to acknowledge the support provided by staff from Curtin University, Australia. 


\section{References}

[1] D.A. Wood, A review and outlook for the global LNG trade, Journal of Natural Gas Science and Engineering, 9 (2012) 16-27.

[2] W. Lim, K. Choi, I. Moon, Current Status and Perspectives of Liquefied Natural Gas (LNG) Plant

Design, Industrial \& Engineering Chemistry Research, 52 (2013) 3065-88.

[3] L. Castillo, R. Nadales, C. Gonzalez, C. Dorao, A. Viloria, Technology selection for liquefied natural gas (LNG) on base-load plants, in: Jornadas de Investigaci6n de la Facultad de Ingenierfa (JIFI\}. Universidad Central de Venezuela, 2010.

[4) L. Castillo, M. Majzoub Dahouk, S. Di Scipio, C.A. Dorao, Conceptual analysis of the precooling stage for LNG processes, Energy Conversion and Management, 66 (2013) 41-47.

[5] A. Vatani,M. Mehrpooya, A. Palizdar, Energy and exergy analyses of five conventional liquefied natural gas processes, International Journal of Energy Research, (2014) 1843-63.

[6] M.Kanoglu, Exergy analysis of multistage cascade refrigeration cycle used for natural gas liquefaction, International Journal of Energy Research, 26 (2002) 763-74.

[7) L. Cipolato, M.C.A. Lirani,T.V.Costa, F.M. Fabrega, J.V.H. d'Angelo, Exergetic optimization of a refrigeration cycle for natural gas liquefaction,31 (2012) 440-44.

[8] D.A. Al-Otaibi, I. Dincer, M. Kalyon, Thermoeconomic optimization of vapor-compression refrigeration systems, International Communications in Heat and Mass Transfer, 31 (2004) 95-107. [9] M. Mehrpooya, A.Jarrahian, M.R. Pishvaie, Simulation and exergy-method analysis of an industrial refrigeration cycle used in NGL recovery units, International Journal of Energy Research, 30 (2006) 1336-51.

[10) A.Cihan, 0. Hac1 haf1zogvlu, K. Kahveci, Energy-exergy analysis and modernization suggestions

for a combined-cycle power plant, International Journal of Energy Research, 30 (2006) 115-26. [11) I.H.Aljundi, Energy and exergy analysis of a steam power plant in Jordan, Applied Thermal Engineering, 29 (2009) 324-28.

[12) S.C. Kaushik, V.S. Reddy,S.K. Tyagi, Energy and exergy analyses of thermal power plants:A review, Renewable and Sustainable Energy Reviews, 15(2011) 1857-72.

[13) M.M.F. Hasan, I.A. Karimi, H.E. Alfadala, Optimizing Compressor Operation in an LNG Plant, in: H. Alfadala, G.V.R. Reklaitis, M.M. El-Halwagi (eds.) Proceedings of the 1st Annual Gas Processing Symposium, Elsevier,Amsterdam, 2009.

[14) G. Lee, R. Smith, X. Zhu, Optimal synthesis of mixed-refrigerant systems for low-temperature processes, Industrial \& engineering chemistry research, 41 (2002) 5016-28. [15) H. Paradowski, M.Bamba, C.Bladanet, Propane Precooling Cycles for Increased LNG Train Capacity, in: 14th International Conference and Exhibitions on Liquefied Natutal Gas Doha, Qatar 2124 March, 2004, pp. 1-18.

[16) L. Castillo, C.A. Dorao, On the conceptual design of pre-cooling stage of LNG plants using propane or an ethane/propane mixture, Energy Conversion and Management, 65 (2013) 140-46. [17) W. Ransbarger, A fresh look at LNG process efficiency, LNG industry, (2007). [18) A . Mortazavi , C. Somers, Y. Hwang, R. Radermacher, P. Rodgers, S. Al-Hashimi, Performance enhancement of propane pre-cooled mixed refrigerant LNG plant, Applied Energy, 93 (2012) 125-31. [19) A . Mortazavi , C. Somers, A . Alabdulkarem , Y. Hwang, R. Radermacher, Enhancement of APCI cycle efficiency with absorption chillers, Energy, 35 (2010) 3877-82.

[20) P.Kalinowski, Y. Hwang, R. Radermacher, S. Al Hashimi, P. Rodgers, Application of waste heat powered absorption refrigeration system to the LNG recovery process, International Journal of Refrigeration, 32 (2009) 687-94.

[21) C. Remeljej, A. Hoadley, An exergy analysis of small-scale liquefied natural gas (LNG) liquefaction processes, Energy, 31 (2006) 2005-19.

[22) P.Hatcher, R. Khalilpour, A. Abbas, Optimisation of LNG mixed-refrigerant processes considering operation and design objectives, Computers \& Chemical Engineering, 41 (2012)123-33. 
[23) M.S. Khan, S. Lee, G.P. Rangaiah, M. Lee, Knowledge based decision making method for the selection of mixed refrigerant systems for energy efficient LNG processes, Applied Energy, 111 (2013) 1018-31.

[24) A. Aspelund, T. Gundersen, J. Myklebust, M.P. Nowak, A. Tomasgard, An optimizationsimulation model for a simple LNG process, Computers \& Chemical Engineering, 34 (2010) 1606-17. [25) W.-s. Cao, X.-s. Lu, W.-s. Lin, A.-z. Gu, Parameter comparison of two small-scale natural gas

liquefaction processes in skid-mounted packages, Applied Thermal Engineering, 26 (2006) 898-904. [26) D.-E. Helgestad, Modelling and optimization of the C3MR process for liquefaction of natural gas, Process Systems Engineering, (2009) 44.

[27) J. Szargut, International Progress in Second Law Analysis Energy 5(1980) 709-18.

[28) X. Xu, J. Liu, C. Jiang, L. Cao, The correlation between mixed refrigerant composition and ambient conditions in the PRICO LNG process, Applied Energy, 102 (2013) 1127-36.

[29) S. Mokhatab, Handbook of liquefied natural gas, Elsevier Science, Burlington, 2013.

[30) J.M. Campbell, Gas conditioning and processing : volume 2, the equipment modules I by John M. Campbell, 8th ed., John M. Campbell and Company, Norman, Oklahoma, 2004.

[31) J.-1. Yoon, K.-H. Choi, H.-S. Lee, H.-J. Kim, C.-H. Son, Assessment of the performance of a natural gas liquefaction cycle using natural refrigerants, Heat and Mass Transfer, 51 (2014) 95-105.

[32) T. He, Y. Ju, Design and Optimization of a Novel Mixed Refrigerant Cycle Integrated with NGL Recovery Process for Small-Scale LNG Plant, Industrial \& Engineering Chemistry Research, 53 (2014) 5545-53. 